\title{
A Bibliometric Assessment of Global Ice Bucket Challenge (Amyotrophic Lateral Sclerosis) Research
}

\author{
Shri Ram \\ Central Library, Thapar University, Patiala, India
}

\author{
Key Words \\ Amyotrophic lateral sclerosis - Ice bucket challenge . \\ Bibliometric analysis
}

\begin{abstract}
Background: This study is a quantitative and qualitative assessment of the global research trends on amyotrophic lateral sclerosis (ALS) (popularly known as Ice Bucket Challenge), through related literatures retrieved from SCOPUS multidisciplinary database for the period 1974-2013. Purpose: This study is aimed at analyzing the literature on ALS in terms of document type, language, annual growth, productive country, journal, authors, subject, and most cited articles. Methods: The bibliographic data for this study was retrieved from the SCOPUS database using keywords 'amyotrophic lateral sclerosis', 'motor neurone disease', 'Charcot disease', 'Lou Gehrig's disease', 'Ice Bucket Challenge' available in title, abstract, and keyword fields of Scopus database from 1974 to 2013. Results: The literature analysis included 21,750 articles during the period from 1974 to 2013 in different areas of ALS. USA was the most productive country in terms of literature produced, while Neurology was the most productive journal. Conclusion: An intensive awareness created by 'Ice Bucket Challenge' has attracted masses, and an
\end{abstract}

intensive growth of literature is pertinent on ALS. The results of this study are expressed in terms of growth of literature, output of individual countries, and authors, and will be helpful in collaborative research in future.

(c) 2016 S. Karger AG, Basel

\section{Introduction}

The evidence of literature on amyotrophic lateral sclerosis (ALS) can be traced back to 1881, when an article on ALS was published in The Lancet journal [1]. Since then, there has been tremendous growth of literature on ALS, discussing the various aspects of the disease. The popularity of ALS became viral over the internet after the launch of 'Ice Bucket Challenge' in August 2014, by eminent people and celebrities from the global world for raising funds for ALS research [2-4]. ALS is a motor neuron disorder, characterized by muscle spasticity, atrophy, dysarthria (difficulty in speaking), dysphagia (difficulty in swallowing), and dyspnea (difficulty in breathing). Because of muscular atrophy, an individual with ALS loses control over self-initiated movement. Stephen Hawking, a famous personality, was a victim of the ALS disorder. It is also named as motor neurone disorder or Lou Gehrig's disor-

\section{KARGER}

E-Mail karger@karger.com

www.karger.com/aon (c) 2016 S. Karger AG, Base

0972-7531/16/0234-0209\$39.50/0
Shri Ram

Central Library

Thapar University

Patiala, Punjab 147004 (India)

E-Mailshriram@thapar.edu 
der, because of its neurodegenerative characteristics. Some reports reveal that in an individual suffering from ALS, dementia, degenerative muscle disorder, and degenerative bone disorder coexist [5]. However, the individual may maintain his/her sensory function such as hearing, sight, touch, smell, and taste as the sensory nerves and the autonomic nervous system remain unaffected [6].

There has been an increasing interest in bibliometric research, especially in medical sciences, for quantitative analysis of literature published in a specific time period. A study on rheumatological research in the European Union reported that the 'statistical measurements of published literature help in understanding the advancement of knowledge over a period of time on a given subject [7]'. This paper is an effort to measure the research advancements in the area of ALS as it has become one of the most sought after disorder subsequent to the launch of 'Ice Bucket Challenge'. This study will help in understanding the trends of research over a period in terms of literature growth on ALS, publication counts of countries, authors, and journals, types of publication; citation patterns; subject coverage; and highly cited articles.

\section{Literature Review}

Bibliometric studies carried out in recent years provide a precise objective for measuring the contribution of an individual and an organization to the advancement of knowledge in a particular field. There are several bibliometric studies on neural research that present trends on literature growth and interpret the results statistically. These studies appear in different journals, dedicated to publish research related to neurology. In recent years, various researches on neurological disorder have been analyzed using the bibliometric methods, such as the publication output on Parkinson's disease [8-10], Alzheimer's disease [11-14], and Guillain-Barre syndrome [15]. Some other bibliometric studies related to these diseases are specialty focused on the contribution by specific countries $[16,17]$. These literature reviews do not produce any evidence on the involvement of research output concerned with ALS. Thus, the objective of this study was to analyze the research trends on literature published on ALS during the period from 1974 to 2013.

\section{Objectives}

The objectives of this study are:

(i) To find the growth of literature on ALS during 19742013;

(ii) To assess document types and language of publication; (iii) To adjudge most productive countries, authors, and journals;

(iv) To assess the shift in research trends in various subjects;

(v) To trace the status of highly cited papers.

\section{Methods}

The data was collected from the SCOPUS multidisciplinary bibliographic database. The keywords 'amyotrophic lateral sclerosis', 'motor neurone disease', 'Charcot disease', 'Lou Gehrig's disease', 'Ice Bucket Challenge' available in the title, abstract, and keyword fields of SCOPUS database were used to extract bibliographic information for the period from 1974 to 2013. The articles published from England, Scotland, Northern Ireland, and Wales were considered as being published from the United Kingdom. The performance of the individual author and institution was determined based on the number of articles written by the author and his/her affiliation address. The citation count was taken as the number of citations scored by each title since its publication till December 2013. The journal impact factor was obtained from the 2013 edition of Journal Citation Report, published by ISI Web of Knowledge. The $h$-index [18], defined as 'the number of papers with citation number greater than or equal to $h$ ', was taken from the SCOPUS database.

\section{Results}

\section{Document Type and Language of Publication}

The 21,750 publications on ALS disorder were distributed in 11 document types, as indexed in the SCOPUS database. These include 13,206 articles as the most popular document type, which comprises $60.72 \%$ of the total production, followed distantly by reviews $(4,421 ; 20.33 \%)$, conference papers $(1,224 ; 5.63 \%)$, letters $(877 ; 4.03 \%)$, editorials $(598 ; 2.75 \%)$, notes $(487 ; 2.24 \%)$, and short surveys $(416 ; 1.91 \%)$. Other document types with less than $1 \%$ contribution were book chapters (156; $0.72 \%)$, errata (71; $0.33 \%)$, books $(11 ; 0.05 \%)$, and conference reviews (4; $0.02 \%)$. There were 372 articles which were not classified in any group. As journal articles represented the majority of document types, 13,206 articles (60.72\%) were further analyzed for interpreting various results. The 21,750 articles were published in 28 different languages; of which, 19,261 articles (88.56\%) were published in English.

\section{Characteristics of Publication}

The characteristics of ALS publication outputs during the period of 40 years from 1974 to 2013 are presented in table 1. 
Table 1. Characteristics of ALS publications analyzed in a 5 years block period

\begin{tabular}{lrlrrrrr}
\hline Year range & \multicolumn{1}{l}{ TP } & \multicolumn{1}{l}{ GR } & AGR & AU & AU/TP & TC & ACPP \\
\hline $1974-1978$ & 507 & -16.24 & 3.25 & 1,245 & 0.41 & 2,307 & 4.55 \\
$1979-1983$ & 574 & 24.75 & 4.95 & 1,618 & 0.35 & 4,406 & 7.68 \\
$1984-1988$ & 788 & 28.13 & 5.63 & 2,521 & 0.31 & 11,268 & 14.30 \\
$1989-1993$ & 1,199 & 55.88 & 11.18 & 4,526 & 0.26 & 35,769 & 29.83 \\
$1994-1998$ & 2,282 & 34.32 & 6.86 & 9,182 & 0.25 & 112,158 & 49.15 \\
$1999-2003$ & 3,186 & 21.68 & 4.34 & 13,210 & 0.24 & 139,502 & 43.79 \\
$2004-2008$ & 5,078 & 44.05 & 8.81 & 22,779 & 0.22 & 180,844 & 35.61 \\
2009-2013 & 8,136 & 45.02 & 9.00 & 43,930 & 0.19 & 113,579 & 13.96 \\
Global total & 21,750 & $1,543.59$ & 38.59 & 99,011 & & 599,833 & \\
Average & & & & & 0.22 & & 27.58
\end{tabular}

$\mathrm{TP}=$ Total publications; $\mathrm{AU}=$ total authors; $\mathrm{TC}=$ total citations; $\mathrm{GR}=$ growth rate; $\mathrm{AGR}=$ annual growth rate; $\mathrm{ACPP}=$ average citation per paper.

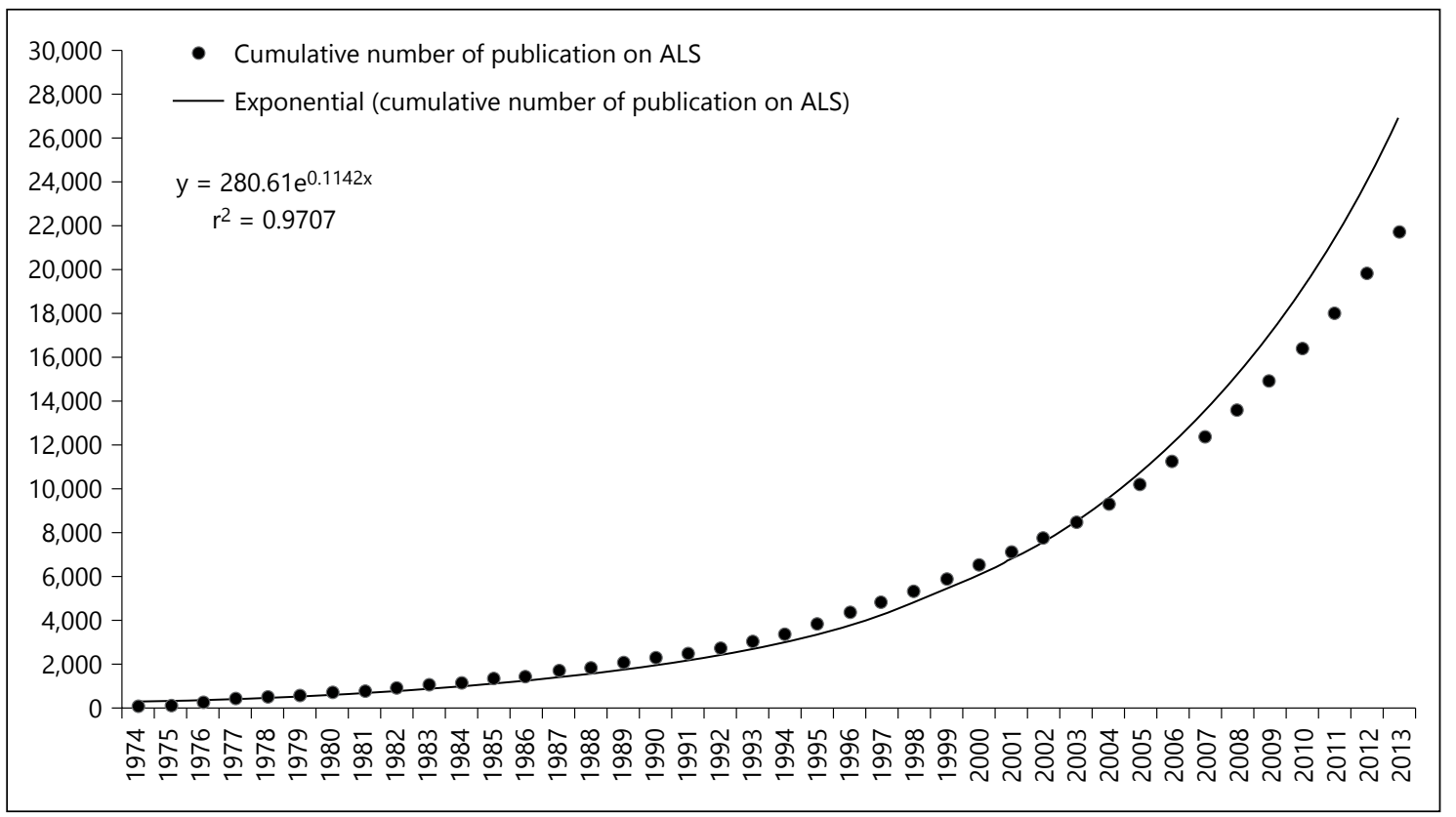

Fig. 1. Cumulative number of publications analyzed in terms of annual growth.

The trends of publication are analyzed in a period of 5 years duration in terms of total number of articles, growth rate (GR), annual GR (AGR), total number of authors, average number of authors, total citations, and average citation per paper (ACPP). It was found that the publication on ALS-related research obtained an overall GR of $1,543.59$ (AGR of 39.59\%) with 507 articles in the period $1974-1978$ to 8136 in $2009-2013$. A total of 99,011 authors, either singly or in joint collaboration published 21,750 articles. On an average, 0.41 authors per ALS publication published articles during the peri- od 1974-1978, while the number steadily decreased to 0.19 in $2009-2013$. The 21,750 articles have accumulated 5, 99,833 citations with an ACPP of 27.58 citations. The articles which were published during the period 1994-1998 have the highest ACPP, though the total number of citations of articles published during the period 2004-2008 was the highest (180,844 citations; table 1).

The data were further analyzed, and it was found that a significant correlation exists between the annual cumulative number of publications and the period of study 
Table 2. Most productive countries in ALS research

\begin{tabular}{|c|c|c|c|c|c|c|}
\hline Country & $\mathrm{TP}$ & \%ТP & IP & $\% \mathrm{IP}$ & $\mathrm{CP}$ & $\% \mathrm{CP}$ \\
\hline United States & 7,475 & 34.37 & 2,538 & 33.95 & 4,937 & 66.05 \\
\hline Japan & 2,375 & 10.92 & 527 & 22.19 & 1,848 & 77.81 \\
\hline Italy & 1,727 & 7.94 & 903 & 52.29 & 824 & 47.71 \\
\hline United Kingdom & 1,677 & 7.71 & 1,326 & 79.07 & 351 & 20.93 \\
\hline Germany & 1,454 & 6.69 & 1,062 & 73.04 & 392 & 26.96 \\
\hline Canada & 1,172 & 5.39 & 848 & 72.35 & 324 & 27.65 \\
\hline France & 1,085 & 4.99 & 714 & 65.81 & 371 & 34.19 \\
\hline Netherlands & 504 & 2.32 & 491 & 97.42 & 13 & 2.58 \\
\hline Spain & 499 & 2.29 & 298 & 59.72 & 201 & 40.28 \\
\hline Australia & 483 & 2.22 & 297 & 61.49 & 186 & 38.51 \\
\hline
\end{tabular}

$\mathrm{TP}=$ Total publications; $\mathrm{IP}=$ independent publications; $\mathrm{CP}=$ collaborated publications.

from 1974 to 2013 (fig. 1). A cumulative progression, in terms of number of publications, was drawn and tested with an exponential model, which can be expressed as follows:

$$
y=280.61 e^{0.1142 x}
$$

Due to the high coefficients of determination $\left(\mathrm{r}^{2}=\right.$ 0.9707), the rate of increase in global publication on ALS is expected to continue. Li et al. [8] reported an increasing trend of publications, which deals with neurological disorders such as Alzheimer's disease, multiple sclerosis, Huntington's disease, and Friedreich's ataxia.

\section{Productive Countries}

The publications share of the 10 most productive countries in ALS is given in table 2. The publication research ranges from 2.22 to $34.37 \%$ during 1974-2013. USA ranks first in the list, with a publications share of 34.37\% during 1974-2013. Japan ranks second, followed by Italy, United Kingdom, and Germany (their global publications share ranging from 10.92 to $6.69 \%$ ). Canada, France, Netherlands, Spain, and Australia rank at 6th10th positions and their global publications share ranges from 5.39 to $2.22 \%$. Among these top 10 productive countries in ALS research, Netherlands has $97.42 \%$ papers produced from Netherlands only, while Japan has least papers $(22.19 \%)$. The United Kingdom has $79.07 \%$ articles, while Germany has $73.04 \%$. Most of the papers published from Japan are published in collaboration with other countries, followed by USA (66.05\%) and Italy (47.71\%).
Table 3. Productive journals publishing ALS research, 1974-2013

\begin{tabular}{llll}
\hline Journals & TP & \%TP & IF (2013) \\
\hline Neurology & 847 & 3.89 & 8.303 \\
Journal of Neurological Sciences & 650 & 2.99 & 2.262 \\
Amyotrophic Lateral Sclerosis, now & & & \\
$\quad$ Amyotrophic Lateral Sclerosis and & & & \\
$\quad$ Frontotemporal Degeneration & 598 & 2.75 & 2.591 \\
Muscle and Nerve & 466 & 2.14 & 2.311 \\
Clinical Neurology & 353 & 1.62 & N/A \\
Acta Neuropathologica & 336 & 1.54 & 9.777 \\
Annals of Neurology & 324 & 1.49 & 11.91 \\
Amyotrophic Lateral Sclerosis and Other & & & \\
$\quad$ Motor Neuron Disorders - Continued & & & \\
$\quad$ as Amyotrophic Lateral Sclerosis now & 293 & 1.35 & 2.591 \\
Journal of Neurology Neurosurgery & & & \\
$\quad$ and Psychiatry & 274 & 1.26 & 5.58 \\
Archives of Neurology & 261 & 1.20 & 7.008 \\
Journal of Neurochemistry & 235 & 1.08 & 4.244 \\
Plos One & 224 & 1.03 & 3.534 \\
Journal of Neurology & 213 & 0.98 & 3.841 \\
Proceedings of the National Academy of & & & \\
$\quad$ Sciences of the United States of America & 199 & 0.91 & 9.809 \\
Neuroscience Letters & 191 & 0.88 & 2.055 \\
Acta Neurologica Scandinavica & 187 & 0.86 & 2537 \\
Experimental Neurology & 176 & 0.81 & 4.617 \\
Brain Research & 175 & 0.80 & 2.828 \\
Neurobiology of Aging & 174 & 0.80 & 4.853 \\
Revue Neurologique & 166 & 0.76 & 0.601 \\
\hline$\quad$ & & & \\
\hline & & &
\end{tabular}

$\mathrm{TP}=$ Total publication; IF = impact factor

\section{Productive Journals}

Table 3 presents the status of 20 most productive journals, which publishes about $29.16 \%$ global literature on ALS. A total of 21,750 articles were published in a wide range of journals, conferences, and books. The journal 
Table 4. Productive authors in ALS research, 1974-2013

\begin{tabular}{|c|c|c|c|c|c|}
\hline Author & Institute & $\mathrm{TP}$ & TC & ACPP & $h$-Index \\
\hline Albert Christian Ludolph & Department of Neurology, Universitat Ulm, Germany & 217 & 4,715 & 21.73 & 40 \\
\hline Peter Nigel Leigh & Trafford Centre for Medical Research, University of Sussex, UK & 186 & 10,863 & 58.40 & 60 \\
\hline Vincent Meininger & $\begin{array}{l}\text { ALS Community Network, Hopital Pitie Salpetriere, Paris, } \\
\text { France }\end{array}$ & 177 & 6,765 & 38.22 & 43 \\
\hline Hiroshi Mitsumoto & $\begin{array}{l}\text { Department of Neurology, Columbia University Medical Center, } \\
\text { New York, USA }\end{array}$ & 156 & 5,863 & 37.58 & 43 \\
\hline Adriano Chiò & $\begin{array}{l}\text { Rita Levi Montalcini Department of Neuroscience, Universita degli } \\
\text { Studi di Torino, Torino, Italy }\end{array}$ & 141 & 4,409 & 31.27 & 43 \\
\hline $\begin{array}{l}\text { Leonard Hendrik } \\
\text { Van Den Berg }\end{array}$ & $\begin{array}{l}\text { Department of Neurology, University Medical Center Utrecht, } \\
\text { Netherlands }\end{array}$ & 137 & 3,541 & 25.85 & 42 \\
\hline Pamela Jean Shaw & Department of Neuroscience, University of Sheffield, UK & 136 & 6,362 & 46.78 & 49 \\
\hline Stanley H. Appel & Department of Neurology, Methodist Hospital Houston, USA & 136 & 7,398 & 54.40 & 53 \\
\hline Wim Robberecht & Department of Neurology, University Hospital Leuven, Belgium & 129 & 6,414 & 49.72 & 50 \\
\hline Michael R.W. Swash & $\begin{array}{l}\text { Departments of Neurology and Neuroscience, Queen Mary, } \\
\text { University of London, UK }\end{array}$ & 127 & 3,701 & 29.14 & 31 \\
\hline Ammar Al Chalabi & $\begin{array}{l}\text { Department of Basic and Clinical Neuroscience, King's College } \\
\text { London, UK }\end{array}$ & 125 & 6,084 & 48.67 & 44 \\
\hline Orla M. Hardiman & Quantitative Neuroimaging Group, Trinity College Dublin, Ireland & 119 & 4,513 & 37.92 & 44 \\
\hline Christopher E.D. Shaw & $\begin{array}{l}\text { Department of Basic and Clinical Neuroscience, King's College } \\
\text { London, UK }\end{array}$ & 115 & 6,367 & 55.37 & 46 \\
\hline Don W.W. Cleveland & $\begin{array}{l}\text { Department of Cellular and Molecular Medicine, University of } \\
\text { California, San Diego, USA }\end{array}$ & 109 & 14,928 & 136.95 & 62 \\
\hline \multirow[t]{2}{*}{ V. Silani } & Department of Neurology, Universita degli Studi di Milano, Italy & 104 & 2,498 & 24.02 & 32 \\
\hline & & 2,114 & 94,421 & 44.66 & \\
\hline
\end{tabular}

$\mathrm{TP}=$ Total publication; $\mathrm{TC}=$ total citation; $\mathrm{ACPP}=$ average citation per paper.

Neurology (IF2013 $=8.303$ ) was ranked first with 847 articles, which was $3.89 \%$ of the total publication on ALS. Journal of Neurological Sciences (IF = 2.262) was ranked second with 650 (2.99\%) articles, followed by Amyotrophic Lateral Sclerosis now Amyotrophic Lateral Sclerosis and Frontotemporal Degeneration (IF $=2.591$ ) with 598 articles (2.75\%), and Muscle and Nerve (466; 2.14\%). Clinical Neurology with 353 articles did not have much impact. Additionally, in the list of most productive journals, the Annals of Neurology had the highest impact factor (11.91).

\section{Most Productive Authors on 'ALS' Research}

The analysis of author's contribution to ALS research was carried out based on the most number of articles published during the period of study. It helps to identify those researchers who have made important contributions in ALS research. A total of 99,011 authors either singly or in joint collaboration published 21,750 articles. Of these authors, it was found that 15 authors have made the highest contribution (table 4). Of these, 'Albert Christian Ludolph' had published the most number of articles on ALS (217 papers) and is the most productive author without author information (116 articles, $2.3 \%$ of 5,109 articles) followed by 'Peter Nigel Leigh' (186 papers) and 'Vincent Meininger' (177 papers). In terms of citation count, 'Don W.W. Cleveland' had scored the most number of citations for 109 papers with an ACPP of 136.95 followed by 'Peter Nigel Leigh' (10,836 citations; ACPP 58.4), and Stanley H. Appel (7,398 citations; ACPP 54.4). The research impact of these authors was found in 
Table 5. Distribution of ALS literature in different subject categories

\begin{tabular}{lrr}
\hline Subject area & TP & \%Share \\
\hline Medicine & 13,464 & 61.90 \\
Neuroscience & 9,870 & 45.38 \\
Biochemistry, Genetics and Molecular Biology & 5,526 & 25.41 \\
Pharmacology, Toxicology and Pharmaceutics & 1,638 & 7.53 \\
Psychology & 604 & 2.78 \\
Agricultural and Biological Sciences & 463 & 2.13 \\
Immunology and Microbiology & 419 & 1.93 \\
Health Professions & 376 & 1.73 \\
Multidisciplinary & 365 & 1.68 \\
Engineering & 300 & 1.38 \\
Nursing & 290 & 1.33 \\
Arts and Humanities & 258 & 1.19 \\
Chemistry & 244 & 1.12 \\
Computer Science & 200 & 0.92 \\
Social Sciences & 159 & 0.73 \\
Environmental Science & 143 & 0.66 \\
Chemical Engineering & 140 & 0.64 \\
Mathematics & 78 & 0.36 \\
Physics and Astronomy & 63 & 0.29 \\
Materials Science & 39 & 0.18 \\
Decision Sciences & 32 & 0.15 \\
Dentistry & 24 & 0.11 \\
Veterinary & 14 & 0.06 \\
Energy & 9 & 0.04 \\
Earth and Planetary Sciences & 7 & 0.03 \\
Business, Management and Accounting & 6 & 0.03 \\
Economics, Econometrics and Finance & 6 & 0.03 \\
\hline & & \\
\hline
\end{tabular}

$\mathrm{TP}=$ Total publication . terms of $h$-Index. 'Don W.W. Cleveland' had the highest $h$-Index value of 62 , followed by 'Peter Nigel Leigh' ( $h$-Index 60), and 'Stanley H. Appel' ( $h$-Index 53; table 4).

\section{Subject Coverage of ALS Papers Published from India}

The ALS documents appeared in 27 different subject categories (SCOPUS Journal Subject classification). The highest publications were related to the subject category Medicine (13,464 publications, $61.90 \%$ share). The other subject categories were Neuroscience $(9,870$ publications, $45.38 \%$ share), Biochemistry, Genetics and Molecular Biology (5,526 publications, 25.41\% share), and Pharmacology, Toxicology and Pharmaceutics (1,638 publications, $7.53 \%$ share). These 4 subjects' have contributed 1,000 and more documents on ALS, and the majority of documents fall into these 4 categories. Being a multidisciplinary area, the subjects have been put into more than one category. The other prominent subject classification of ALS research is given in table 5.

\section{Institutes' Research Performances}

The contribution of top 10 most productive institutes is given in table 6. Massachusetts General Hospital, USA is the most productive institute with 383 publications, which is $1.76 \%$ of the total global output. King's College London was ranked second (351; $1.61 \%$ share) and VA Medical Center, USA $(322 ; 1.48 \%)$ third. In terms of citation count, Massachusetts General Hospital, USA ranked one (29,327 citations), followed by Kings College London (16,928 citations), and Johns Hopkins University, USA (16,636 citations). Impact in terms of ACPP, Johns Hopkins University, USA topped the rank (84.02 citations per paper), followed by Massachusetts General Hospital, USA (76.57 citations per paper), and Johns Hopkins School of Medicine, USA (71.61 citations per paper).

\section{Most Frequently Cited Paper}

The research impact of any work published in the form of an article is assessed in terms of citation scored by the article since its publication. Marx and Cardona [19] dis- 
Table 6. Most productive institutions on ALS research

\begin{tabular}{|c|c|c|c|c|}
\hline Institutes & $\mathrm{TP}$ & \%Share & $\mathrm{TC}$ & $\mathrm{ACPP}$ \\
\hline Massachusetts General Hospital, USA & 383 & 1.76 & 29,327 & 76.57 \\
\hline King's College London, UK & 351 & 1.61 & 16,928 & 48.23 \\
\hline VA Medical Center, USA & 322 & 1.48 & 10,763 & 33.43 \\
\hline Hopital Pitie Salpetriere, France & 248 & 1.14 & 6,297 & 25.39 \\
\hline The University of British Columbia, Canada & 247 & 1.14 & 12,290 & 49.76 \\
\hline The Johns Hopkins School of Medicine, USA & 225 & 1.03 & 16,113 & 71.61 \\
\hline Universitat Ulm, Germany & 222 & 1.02 & 4,153 & 18.71 \\
\hline University Medical Center Utrecht, Netherlands & 199 & 0.91 & 4,245 & 21.33 \\
\hline Johns Hopkins University, USA & 198 & 0.91 & 16,636 & 84.02 \\
\hline University of California, San Francisco, USA & 192 & 0.88 & 10,519 & 54.79 \\
\hline
\end{tabular}

$\mathrm{TP}=$ Total publications; $\mathrm{TC}=$ total citations.

Table 7. Characteristics of most frequently cited articles on ALS

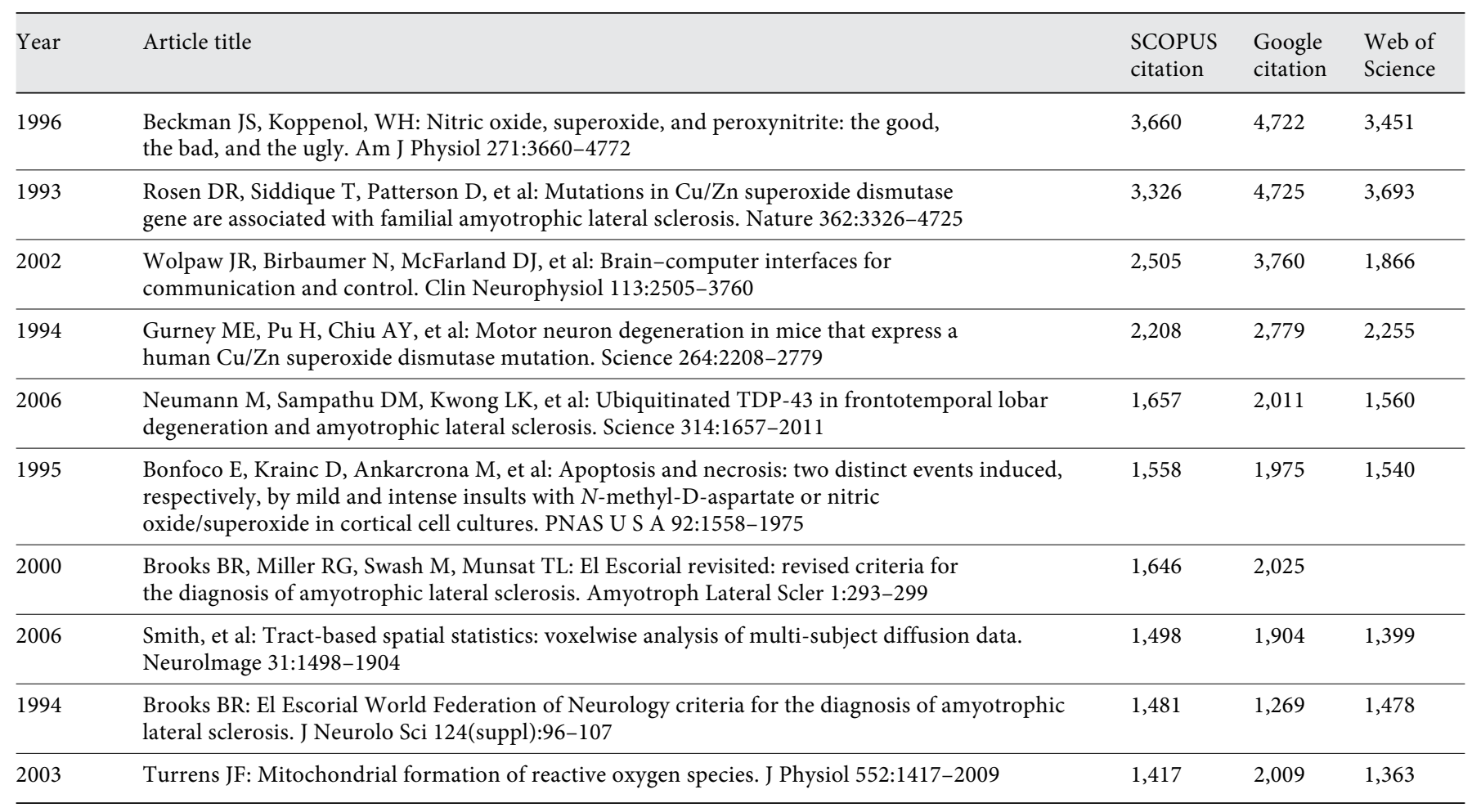

cussed the citation activity in terms of time dependency of an article and refer to it as 'sales figure' of the article. Table 2 presents the status of 10 articles on ALS, which are most frequently cited. The article 'Nitric Oxide, Superoxide, and Peroxynitrite: The Good, the Bad, and the Ugly' was the most frequently cited article on ALS, with an average citation of 203.33 citations per year since its publication in 1996. The citations slightly increased after it was published and reached a maximum after 6 years. However, a decreasing trend can be seen after 6 years (i.e. 2002). This article basically deals with the effect of nitric oxide, superoxide, and peroxynitrite on internal messenger services. Furthermore, antibodies to nitrotyrosine have revealed nitration in human atherosclerosis, myocardial ischemia, septic and distressed lung, inflammatory bowel disease, and ALS [20]. Table 7 also gives the 


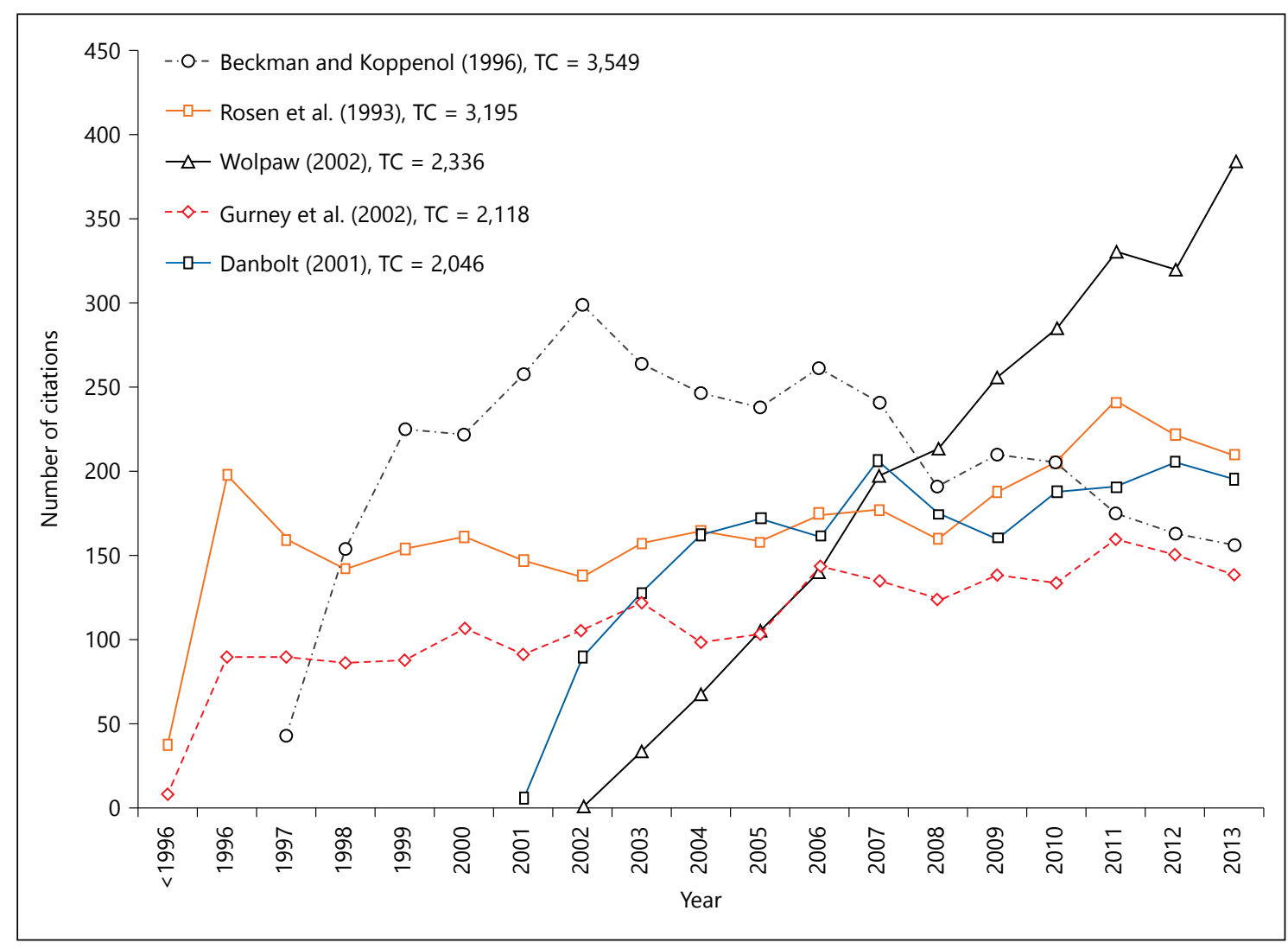

Fig. 2. Characteristics of 5 most cited articles on ALS.

citation count by 3 different databases such as SCOPUS, Google Citation, and Web of Science. A significant difference can be observed in the number of citation data available through these 3 sources. These variations in terms of quantity and quality of citation through these sources have always been debatable and will be used as a measure of research impact [21].

The citation analysis of the top cited articles since their publication describes the research impact in that particular subject field. Several studies have assessed the impact based on the citation count. Aversa [22] reported 2 types of citation patterns: 'delayed rise - slow decline' and 'early rise - rapid decline'. Various other terminologies to such kinds of citation pattern, where 'delayed rise - slow decline' papers often turn out to be more valuable and influential. According to Stent [23], these are known as 'scientific prematurity', while Garfield [24] termed them as 'delayed recognition' and Van Raan [25] as 'sleeping beauties' . Fitting into these hypotheses, 2 papers on ALS - Rosen et al. (1993) (3,326 citations) and Gurney et al. (1994) (2,208 citations) - show 'slow rise - delayed decline' citation pattern and these articles are still being well cited even after 20 years of their publication. One article by Danbolt N.C. (2001) scored 2,177 citations and shows an early rise in the citation but starts decline after 6 years of its publication. While the article by Wolpaw et al. (2002) with a citation of 2,505 is continuously increasing year after year (fig. 2).

\section{Discussion}

ALS is a neurodegenerative motor neuron disorder, characterized by muscle spasticity, atrophy, dysarthria, dysphagia, and dyspnea. Because of muscular atrophy, an individual with ALS loses control over self-initiated movement. The ALS gained publicity with the involvement of celebrities worldwide in a campaign known as 'Ice Bucket Challenge'. The SCOPUS database had indexed 21,750 articles during the period 1974-2013. There were 16 document types used in ALS research publications, where $60.72 \%$ documents were published as journal articles. Though journal articles were the most prominent mode of publication, there were also conference pa- 
pers which have a fair amount of publication share. English was the most predominant language of communication. The articles on ALS research had an AGR of $39.59 \%$ per year during the period of study. All the papers were published by about 0.22 authors per paper. There was a high coefficient of determination, which illustrates a continued growth trend in future. USA was the most productive country with a share of $34.37 \%$ of global publication. Japan had more collaborative papers shared with other countries; $77.81 \%$ papers published from Japan were collaborated papers. Papers published from the Netherlands were least collaborated; $97.42 \%$ papers were published by authors from Netherlands only. The research in developing countries, such as India, does not show any progressive impact on research-related to ALS and ranked far behind in the list. ALS research was published in a wide range of journals, with the journal 'Neurology' being the most productive journal. 'Massachusetts General Hospital, USA' was the most productive in- stitution in terms of the number of publications on ALS. There was a correlation between the $h$-Index and citations. The authors with highest citations have a higher $h$-Index value. However, the most productive author does not have a high $h$-Index value.

There is a need to understand the importance of these diseases and the results reported in this study shall help the scientists and other stakeholders in collaboration for future research.

\section{Author Contribution}

All work on the manuscript was done by Shri Ram.

\section{Disclosure Statements}

The author declares no conflict of interest. This study received no funding or sponsorship of any form.

\section{References}

1 Ferrier D: National hospital for the paralysed and epileptic. Cases of amyotrophic lateral sclerosis. Lancet 1881;117:822-823.

2 INDEPENDENT: George Bush Delivers Possibly the Best ALS Ice Bucket Challenge Yet (retrieved August 20, 2014).

3 Metro: 10 of the Best Celebrity Ice Bucket Challenges (retrieved August 20, 2014).

4 Guardian: The 10 Best Celebrity Takes on the Ice Bucket Challenge (retrieved August 20, 2014).

5 Johnson JO, Mandrioli J, Benatar M, Abramzon Y, Van Deerlin VM, Trojanowski JQ, et al: Exome sequencing reveals VCP mutations as a cause of familial ALS. Neuron 2010;68: 857-864.

6 NIH: Amyotrophic Lateral Sclerosis (ALS) Fact Sheet. http://www.ninds.nih.gov/ disorders/amyotrophiclateralsclerosis/detail_als.htm.

7 Mela GS, Cimmino MA: An overview of rheumatological research in the European Union. Ann Rheum Dis 1998;57:643-647.

8 Li T, Ho YS, Li CY: Bibliometric analysis on global Parkinson's disease research trends during 1991-2006. Neurosci Lett 2008;441: 248-252.

9 Ansari MA, Khan A: Parkinson's disease: a bibliometric profile. Trend Info Manag 2008; 3:58-68.
10 Ponce FA, Lozano AM: The most cited works in Parkinson's disease. Mov Disord 2011;26: 380-390.

11 Ansari MA, Gul S, Yaseen M: Alzheimer's disease: a bibliometric study. Trend Inform Manag 2006;2:130-140.

12 Sorensen AA: Alzheimer's disease research: scientific productivity and impact of the top 100 investigators in the field. J Alzheimers Dis 2009;16:451-465.

13 Sorensen AA, Seary A, Riopelle K: Alzheimer's disease research: a COIN study using coauthorship network analytics. Proced Soc Behav Sci 2010;2:6582-6586.

14 Chen H, Wan Y, Jiang S, Cheng Y: Alzheimer's disease research in the future: bibliometric analysis of cholinesterase inhibitors from 1993 to 2012. Scientometrics 2014;98:18651877.

15 Ram S: India's contribution on 'GuillainBarre syndrome': mapping of 40 years research. Neurol India 2013;61:375-382.

16 Gupta BM, Bala A: Alzheimer's disease research in India: a scientometric analysis of publications output during 2002-2011. Res Neurol 2013;11:204542.
17 Gupta BM, Bala A: Parkinson's disease in India: an analysis of publications output during 2002-2011. Int J Nutr Pharmacol Neurol Dis 2013;3:254-262.

18 Hirsch JE: An index to quantify an individual's scientific research output. Proc Natl Acad Sci U S A 2005;102:16569-16572.

19 Marx W, Cardona M: The impact of solid state communications in view of the ISI citation data, Solid State Commun 2003;127:323336.

20 Beckman JS, Koppenol WH: Nitric oxide, superoxide, and peroxynitrite: the good, the bad, and ugly. Am J Physiol 1996;271(5 pt 1): C1424-C1437.

21 De Winter JCF, Zadpoor AA, Dodou D: The expansion of Google Scholar versus Web of Science: a longitudinal study. Scientometrics 2014;98:1547-1565.

22 Aversa ES: Citation patterns of highly cited papers and their relationship to literature aging: a study of the working literature. Scientometrics 1985;7:383-389.

23 Stent GS: Prematurity and uniqueness in scientific discovery. Sci Am 1972;227:84-93.

24 Garfield E: Premature discovery or delayed recognition - why. Curr Contents 1980;21: 5-10.

25 Van Raan AFJ: Sleeping beauties in science. Scientometrics 2004;59:467-472. 